\title{
Direct Evidence For a Stimulatory Effect of Hyperglycemia Per Se on Peripheral Glucose Disposal in Type II Diabetes
}

\author{
Brunella Capaldo, Donatella Santoro, Gabriele Riccardi, Nicola Perrotti, and Luigi Saccà \\ Department of Internal Medicine, Second School of Medicine, University of Naples, Italy 80131
}

\section{Abstract}

The effect of hyperglycemia per se on glucose uptake by muscle tissue was quantitated in six controls and six type II diabetics by the forearm technique, under conditions of insulin deficiency induced by somatostatin (SRIF) infusion $(0.7 \mathrm{mg} / \mathrm{h})$. Blood glucose concentration was clamped at its basal value during the first $60 \mathrm{~min}$ of SRIF infusion and then raised to $\sim 200 \mathrm{mg} / \mathrm{dl}$ by a variable glucose infusion. Plasma insulin levels remained at or below $5 \mu \mathrm{U} / \mathrm{ml}$ during SRIF infusion, including the hyperglycemic period. No appreciable difference between controls and diabetics was present in the basal state as to forearm glucose metabolism. After $60 \mathrm{~min}$ of SRIF infusion and euglycemia, forearm glucose uptake fell consistently from $2.1 \pm 0.7 \mathrm{mg} \cdot$ liter $^{-1} \cdot \mathrm{min}^{-1}$ to $1.0 \pm 0.6(P<0.05)$ and from $1.7 \pm .2$ to $0.4 \pm 0.3$ $(P<0.02)$ in the control and diabetic groups, respectively. The subsequent induction of hyperglycemia caused a marked increase in both the arterial-deep venous blood glucose difference $(P$ $<0.02-0.01)$ and forearm glucose uptake $(P<0.01-0.005)$. However, the response in the diabetic group was significantly greater than that observed in controls. The incremental area of forearm glucose uptake was $276 \pm 31 \mathrm{mg} \cdot \operatorname{liter}^{-1} \cdot 90 \mathrm{~min}$ and $532 \pm 81$ in the control and diabetic groups, respectively ( $P$ $<0.02$ ). In the basal state, the forearm released lactate and alanine both in controls and diabetic subjects at comparable rates. No increment was observed after hyperglycemia, despite the elevated rates of glucose uptake.

It is concluded that (1) hyperglycemia per se stimulates forearm glucose disposal to a greater extent in type II diabetics than in normal subjects; and (2) the resulting increment of glucose disposal does not accelerate the forearm release of three carbon compounds. The data support the hypothesis that hyperglycemia per se may play a compensatory role for the defective glucose disposal in type II diabetes.

\section{Introduction}

Muscle glucose uptake is of primary importance in extrasplanchnic glucose disposal and has been traditionally regarded as an exquisitely insulin-dependent process. Recent studies, however, demonstrated that hyperglycemia per se, in circumstances of severe insulin deficiency, may considerably stimulate glucose uptake by peripheral tissues, including the skeletal muscle (1). These observations raise critical questions regarding the sig-

Address correspondence to Dr. Saccà, Institute of Internal Medicine I, Second School of Medicine, Via S. Pansini, 5, 80131 Napoli, Italy.

Received for publication 23 November 1984 and in revised form 25 November 1985 .

J. Clin. Invest.

(C) The American Society for Clinical Investigation, Inc.

$0021-9738 / 86 / 04 / 1285 / 06 \$ 1.00$

Volume 77, April 1986, 1285-1290 nificance of the well-documented peripheral insulin resistance associated with type II diabetes mellitus (2-6). In this disease, characteristically, peripheral tissues have a reduced ability to take up glucose when they are exposed to elevated insulin levels (2-6). This finding clearly supports the existence of a defect in insulin-mediated glucose utilization. The possibility, however, that the stimulatory effect of hyperglycemia per se may also be altered in this disease, thus contributing to the defective glucose disposal, has not been explored. Since peripheral tissues, and specifically the muscle tissue, are regulated not only by insulin but by glucose per se as well (1), it becomes critical to differentiate the relative roles of insulin and glucose for a full understanding of the mechanisms underlying the impaired glucose disposal of type II diabetes.

The current study was, therefore, undertaken to determine whether, in type II diabetes, hyperglycemia per se (in the presence of low, fixed insulin levels) maintains unaltered its ability to promote glucose disposal by peripheral tissues. The forearm technique was employed in this study to get specific information on muscle glucose metabolism, given the importance of this site in the overall response of peripheral glucose disposal (7).

\section{Methods}

Subjects. Two groups of subjects were studied. The diabetic group consisted of six type II diabetic patients (five males and one female, aged 34-61 yr). The control group consisted of six healthy volunteers (five males and one female, aged 35-57 yr) matched for sex, age, and relative weight. None had a family history of diabetes mellitus or any abnormality of the oral glucose tolerance (8). All subjects were within 15\% of their ideal body weight (Metropolitan Life Insurance Tables, 1959) and were consuming a weight-maintaining diet containing at least $200 \mathrm{~g}$ of carbohydrate for $3 \mathrm{~d}$ before the study. The clinical and metabolic characteristics of the subjects are summarized in Table I. The diabetic patients had evidenced overt diabetes for a mean duration $( \pm \mathrm{SE})$ of $5 \pm 1.6 \mathrm{yr}$. Five subjects were controlled by sulfonylurea therapy and one by normocaloric low carbohydrate diet alone. Those subjects treated with oral hypoglycemic agents had these drugs withdrawn for at least 2 wk before the study. The day before the study, beginning at 1 p.m., diabetic patients were treated with continuous subcutaneous insulin infusion, by using a portable infusion pump to achieve gradually normoglycemia. The basal insulin infusion ranged from 0.7 to $1.5 \mathrm{U} / \mathrm{h}$. Furthermore, boluses of regular insulin were given before the main meals. Insulin infusion was discontinued $4 \mathrm{~h}$ before initiating the experiment. Informed consent was obtained from all participants. The experimental protocol was approved by the Ethical Committee of the University of Naples School of Medicine.

Procedures. All subjects were studied in the postabsorptive state after a 15-17-h overnight fast. The forearm perfusion technique $(9,10)$ was used as previously described (1). A teflon catheter was inserted in a retrograde manner into a forearm vein and threaded deeply into the forearm tissue until its tip was no longer palpable under the skin. Under these conditions, the effluent venous blood drained predominantly muscle tissue. A second teflon catheter was introduced percutaneously into the ipsilateral brachial artery for blood sampling and for infusion of indocyanine green dye (Cardio-Green, Hynson, Westcott \& Dunning, Baltimore, MD) to measure forearm blood flow. A contralateral vein was 
Table I. Clinical and Metabolic Characteristics of the Subjects

\begin{tabular}{llllllrr} 
& $\begin{array}{l}\text { Sex } \\
(\mathrm{M} / \mathrm{F})\end{array}$ & $\begin{array}{l}\text { Relative } \\
\text { weight }\end{array}$ & Age & $\begin{array}{l}\text { Fasting blood } \\
\text { glucose }\end{array}$ & $\begin{array}{l}\text { Fasting serum } \\
\text { insulin }\end{array}$ & $\begin{array}{l}\text { HbA } \\
\text { of diabetes }\end{array}$ \\
\hline & & $\%$ & $y r$ & $m g / d l$ & $\mu U / m l$ & $\%$ & $\%$ \\
Controls $(n=6)$ & $5 / 1$ & $100 \pm 2.1$ & $48 \pm 3.5$ & $80 \pm 3.0$ & $5 \pm 1.5$ & $6.7 \pm 0.8$ & $10.2 \pm 0.9$ \\
Diabetics $(n=6)$ & $5 / 1$ & $100 \pm 3.0$ & $48 \pm 3.7$ & $266 \pm 27$ & $5 \pm 0.8$ & $5 \pm 1.6$ \\
\hline
\end{tabular}

* Data are mean $\pm \mathrm{SE}$.

also cannulated for the infusion of the test substances. $5 \mathrm{~min}$ before and during each sampling period, a sphygmomanometer cuff placed around the wrist was inflated $100 \mathrm{mmHg}$ above the systolic blood pressure to exclude the hand from the circulation. Soon after blood collection, indocyanine green dye was infused through the arterial catheter at a rate of $3 \mathrm{ml} / \mathrm{min}$ while keeping inflated the cuff. After 4 to $5 \mathrm{~min}$, a venous blood sample was taken to measure the plasma concentration of the dye. The infusion of indocyanine green was then stopped and the arterial catheter was kept patent in the intervals between samplings by intermittent saline infusion. At the end of the study, forearm volume was measured in a large plastic cylinder by water displacement from the tip of the arterial catheter to the upper edge of the wrist cuff.

Experimental protocol. After the basal blood samples were taken, a somatostatin (SRIF) ${ }^{1}$ infusion was started and maintained throughout the study at a rate of $0.7 \mathrm{mg} / \mathrm{h}$. During the first $60 \mathrm{~min}$ of SRIF infusion, blood glucose concentration was clamped at its basal value by a variable glucose infusion. Thereafter, the glucose infusion rate was increased so as to raise gradually blood glucose concentration to $200 \mathrm{mg} / \mathrm{dl}$ during the next $90 \mathrm{~min}$. Arterial and venous blood samples were simultaneously collected in the basal state and during the test period at 30-60-min intervals.

An additional group of experiments was performed to determine whether SRIF exerts a direct effect on muscle glucose uptake. The group consisted of three normal subjects and one type II diabetic, whose plasma glucose was normalized according to the procedure described above. In these experiments, SRIF was infused into the brachial artery at a rate of $3.6 \mu \mathrm{g} / \mathrm{h}$ during the first $20 \mathrm{~min}$ and $7.2 \mu \mathrm{g} / \mathrm{h}$ from 20 to $40 \mathrm{~min}$. These rates were chosen so as to expose the forearm tissues to a comparable SRIF concentration to that conceivably achieved with systemic SRIF infusion $(0.7 \mathrm{mg} / \mathrm{h})$, considering that forearm blood flow represents $\sim 1 \%$ of cardiac output. Simultaneous arterial and venous blood sampling was performed together with blood flow measurement in the basal state and at the end of each infusion period according to the technique described above.

Analytical methods. Blood glucose concentration was measured by the glucose oxidase method (11). Plasma insulin and C-peptide concentrations were measured by radioimmunoassay $(12,13)$. The plasma concentration of indocyanine green dye was measured spectrophotometrically. Lactate, alanine, and beta-hydroxy-butyrate concentrations were measured in perchloric extracts of whole blood by using enzymatic procedures (14-16).

Calculations. Forearm blood flow was estimated by dividing the green dye infusion rate by its concentration in the venous plasma and converted to blood flow according to the hematocrit. No correction for recirculation was necessary since the concentration of recirculated dye (as determined in the plasma samples from the contralateral vein) was found to be negligible ( $<5 \%)$. Forearm uptake or output for each substrate was calculated by multiplying its arterial-deep venous (A-dV) concentration difference by the forearm blood flow and normalized by the forearm volume in liters. The values of forearm glucose uptake were corrected for the increasing arterial glucose concentration by using a 1-min transit time for

1. Abbreviations used in this paper: A-dV, arterial-deep venous; SRIF, somatostatin. glucose across the forearm, as previously determined (17). Statistical analysis was performed by the two-way analysis of variance and Bonferroni's inequality (18) (intragroup comparisons) or the $t$ test for unpaired samples (control vs. diabetic subjects). Data are presented as the mean \pm SEM.

\section{Results}

As shown in Table II, the basal insulin concentration was similar in the control and diabetic group, and remained at or below 5 $\mu \mathrm{U} / \mathrm{ml}$ during SRIF infusion. Plasma C-peptide levels fell remarkably in response to SRIF and remained suppressed for the entire experimental period in both groups $(P<0.01)$. As expected, arterial blood beta-hydroxy-butyrate promptly rose in response to SRIF to a similar extent in normal and diabetic subjects, and remained markedly elevated throughout the study.

The changes in blood glucose and forearm glucose metabolism are depicted in Fig. 1. In the basal state, arterial blood glucose was slightly but not significantly higher in the diabetics $(P=\mathrm{NS})$. During the euglycemic period (0-60 min), blood glucose concentration remained at nearly basal levels both in controls and in diabetics. Then, it progressively rose reaching comparable levels $(\sim 200 \mathrm{mg} / \mathrm{dl})$ in the two groups at $150 \mathrm{~min}$. The A-dV blood glucose difference decreased significantly from the basal value of $4 \pm 0.6$ and $5 \pm 0.4 \mathrm{mg} / \mathrm{dl}$ to $1 \pm 0.8$ and $1 \pm 0.9$ in the control and diabetic group, respectively, after $60 \mathrm{~min}$ of SRIF infusion (euglycemia). Induction of hyperglycemia caused the A-dV blood glucose difference to increase consistently in both groups, despite insulin deficiency $(P<0.02-0.01)$. However, the values attained in the diabetic subjects were twofold higher than those in the control group, despite identical blood glucose levels $(27 \pm 5$ vs. $13 \pm 2 \mathrm{mg} / \mathrm{dl}$, respectively, at $90 \mathrm{~min} ; P<0.05)$. The changes in forearm glucose uptake paralleled those observed for the A-dV difference, since the blood flow remained unchanged. Forearm glucose uptake decreased consistently at 60 min after SRIF infusion (from $2.1 \pm 0.7 \mathrm{mg} \cdot \operatorname{liter}^{-1} \cdot \mathrm{min}^{-1}$ to $1.0 \pm 0.6(P<0.05)$ and from $1.7 \pm 0.2$ to $0.4 \pm 0.3(P<0.02)$ in the control and diabetic group, respectively). Hyperglycemia, on the other hand, stimulated markedly forearm glucose disposal in both groups. The values reached in the control group were $5.0 \pm 0.93,6.0 \pm 0.78$, and $5.7 \pm 1.2 \mathrm{mg} \cdot \operatorname{liter}^{-1} \cdot \mathrm{min}^{-1}$ at 90,120 , and $150 \mathrm{~min}$, respectively. In the diabetics, glucose uptake rose to $9.3 \pm 1.6(P<0.05), 9.1 \pm 1.3(0.1>P>0.05)$, and $7.2 \pm 1.2$ $\mathrm{mg} \cdot \operatorname{liter}^{-1} \cdot \mathrm{min}^{-1}$ at 90,120 , and $150 \mathrm{~min}$, respectively. Since the maximal increment in forearm glucose uptake did not occur at the same time in all subjects, we also evaluated the incremental area of glucose uptake over the entire study period. A highly significant difference between the two groups was found $(532 \pm 81$ $\mathrm{mg} \cdot \operatorname{liter}^{-1} \cdot 90 \mathrm{~min}^{-1}$ and $276 \pm 30$ in the diabetic and control group, respectively; $P<0.02$ ). 
Table II. Plasma Insulin, C-peptide, and Arterial Blood Beta-hydroxy-butyrate Concentrations in Control and Diabetic Subjects during Infusion of SRIF and Glucose*

\begin{tabular}{|c|c|c|c|c|c|}
\hline & 0 & 60 & 90 & 120 & 150 \\
\hline & $\min$ & $\min$ & $\min$ & $\min$ & $\min$ \\
\hline \multicolumn{6}{|c|}{ Plasma insulin $(\mu U / m l)$} \\
\hline Controls $(n=6)$ & $5 \pm 1.2$ & $3 \pm 0.4$ & $3 \pm 0.6$ & $3 \pm 0.4$ & $3 \pm 0.4$ \\
\hline Diabetics $(n=6)$ & $7 \pm 1.9$ & $5 \pm 2.0$ & $4 \pm 1.8$ & $4 \pm 1.7$ & $5 \pm 1.6$ \\
\hline \multicolumn{6}{|c|}{ Plasma C-peptide (nmol/liter) } \\
\hline Controls $(n=6)$ & $0.32 \pm 0.05$ & $0.07 \pm 0.01$ & $0.03 \pm 0.006$ & $0.03 \pm 0.005$ & $0.02 \pm 0.008$ \\
\hline Diabetics $(n=6)$ & $0.13 \pm 0.06$ & $0.03 \pm 0.01$ & $0.02 \pm 0.003$ & $0.02 \pm 0.004$ & $0.01 \pm 0.000$ \\
\hline \multicolumn{6}{|c|}{ Arterial blood beta-OH butyrate $(m g / d l)$} \\
\hline Controls $(n=6)$ & $0.39 \pm 0.05$ & $2.36 \pm 0.95$ & $3.11 \pm 1.0$ & $3.31 \pm 1.0$ & $3.54 \pm 1.12$ \\
\hline Diabetics $(n=6)$ & $1.50 \pm 0.42$ & $3.30 \pm 0.61$ & $3.91 \pm 0.64$ & $4.30 \pm 0.74$ & $3.97 \pm 0.79$ \\
\hline
\end{tabular}

* Data are mean $\pm \mathrm{SE}$. Baseline values $(0 \mathrm{~min})$ represent the mean of two observations taken at 15 -min intervals.

The response of forearm lactate metabolism is illustrated in Table III. Arterial blood lactate concentration did not change appreciably throughout the experiment in both groups. Basal forearm lactate output was slightly higher in the diabetic group, but the difference did not reach statistical significance. In normal subjects, forearm lactate output was transiently inhibited during hyperglycemia and then returned slowly to nearly basal values. In the diabetic subjects, forearm lactate output remained unchanged for the entire study period. In no instance did the forearm release lactate at higher rates than those of the basal state in either group of subjects.

The changes in alanine metabolism are illustrated in Table III. Arterial blood alanine concentration remained unchanged throughout the study both in controls and diabetics. In normal

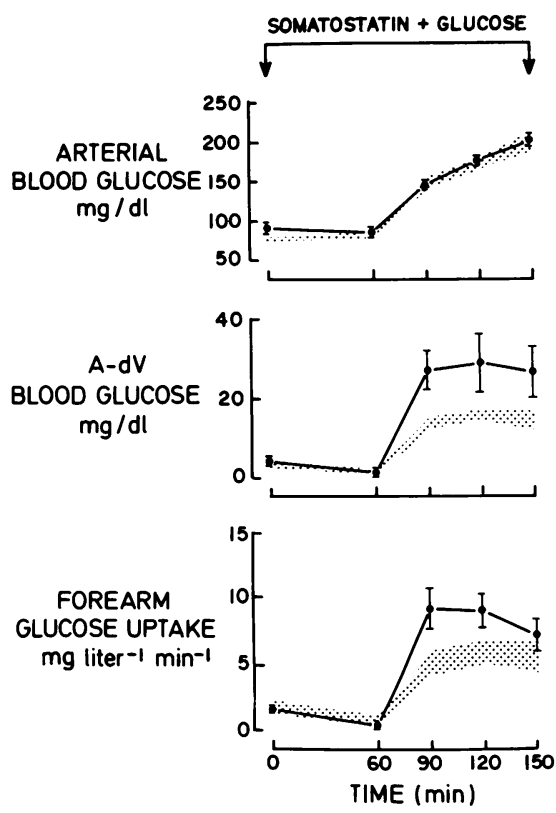

Figure 1. Changes in arterial blood glucose concentration, A-dV blood glucose difference, and forearm glucose uptake induced by SRIF and glucose infusion in type II diabetics $(n=6)$. The shaded area indicates the response (mean $\pm \mathrm{SE}$ ) of the control group $(n=6)$. The baseline values $(0 \mathrm{~min})$ represent the mean of two observations taken at 15 -min intervals. subjects, forearm alanine output fell rapidly after hyperglycemia $(P<0.02)$. In contrast, in the diabetic group, forearm alanine output remained stable throughout the study period.

As shown in Table IV, the estimated forearm blood flow remained practically unchanged throughout the experimental period in both groups of subjects. The effects of intraarterial SRIF infusion on arterial blood glucose, A-dV blood glucose difference, and forearm glucose uptake are reported in Table V. The data of the diabetic patient were combined with those of controls since they were identical. Arterial blood glucose remained stable for the entire study period. Both the A-dV blood glucose difference and forearm glucose uptake were not significantly modified by intraarterial SRIF infusion. Plasma insulin concentration $(7 \pm 2 \mu \mathrm{U} / \mathrm{ml})$ was unaffected by SRIF infusion. The estimated forearm blood flow was $43.3 \pm 5.6 \mathrm{ml}^{-1}$. liter $^{-1} \cdot \mathrm{min}^{-1}$ in the basal state, $42.5 \pm 5.9$ and $42.0 \pm 5.8$ after 20 and $40 \mathrm{~min}$ of the infusion, respectively.

\section{Discussion}

This study attempted to determine whether the stimulatory effect of hyperglycemia per se is normally operative in type II diabetes. For this aspect to be correctly examined in vivo, the tissue(s) under study must be exposed to elevated glucose concentrations while keeping the insulin level as low as possible and stable throughout the experiment. To this end, SRIF was employed to suppress insulin secretion during glucose infusion. Furthermore, several precautions were taken to strengthen the condition of insulinopenia: (1) A 60-min SRIF infusion preceded the hyperglycemic phase of the study; (2) In the diabetics, the basal insulin infusion was kept at as low a rate as possible and was discontinued $4 \mathrm{~h}$ before the study to allow the consequences of a likely peripheral hyperinsulinization to be dissipated; and (3) A dose of SRIF as high as $0.7 \mathrm{mg} / \mathrm{h}$ was used. Similar doses $(0.6 \mathrm{mg} / \mathrm{h})$ have been recently reported to induce a virtually complete suppression of insulin secretion in man, as judged by the fall in the splanchnic C-peptide output (19). In agreement with these previous observations, the C-peptide data in the present study indicate that insulin secretion must have been suppressed in both groups of subjects. This is not equally well reflected in the circulating insulin levels which, although remained at or below $5 \mu \mathrm{U} / \mathrm{ml}$ despite hyperglycemia, were not as deeply suppressed 
Table III. Arterial Blood Lactate, Forearm Lactate Balance, Arterial Blood Alanine and Forearm Alanine Balance in Control and Diabetic Subjects during Infusion of SRIF and Glucose*

\begin{tabular}{|c|c|c|c|c|c|}
\hline & 0 & 60 & 90 & 120 & 150 \\
\hline & $\min$ & $\min$ & $\min$ & $\min$ & $\min$ \\
\hline \multicolumn{6}{|c|}{ Arterial blood lactate $(m g / d l)$} \\
\hline Controls $(n=6)$ & $5.9 \pm 0.85$ & $5.4 \pm 0.75$ & $6.6 \pm 1.10$ & $6.3 \pm 0.85$ & $6.5 \pm 1.10$ \\
\hline Diabetics $(n=6)$ & $6.7 \pm 0.80$ & $6.1 \pm 0.80$ & $6.4 \pm 0.60$ & $6.8 \pm 0.65$ & $7.0 \pm 0.60$ \\
\hline \multicolumn{6}{|c|}{ Forearm lactate balance $\ddagger\left(\mu g \cdot\right.$ liter $\left.^{-1} \cdot \mathrm{min}^{-1}\right)$} \\
\hline Controls $(n=6)$ & $-277 \pm 235$ & $-495 \pm 235$ & $+220 \pm 225$ & $0 \pm 161$ & $-385 \pm 105$ \\
\hline Diabetics $(n=6)$ & $-465 \pm 105$ & $-600 \pm 165$ & $-560 \pm 215$ & $-420 \pm 115$ & $-420 \pm 80$ \\
\hline \multicolumn{6}{|c|}{ Arterial blood alanine $(m g / d l)$} \\
\hline Controls $(n=6)$ & $2.26 \pm 0.25$ & $2.05 \pm 0.26$ & $2.43 \pm 0.23$ & $2.58 \pm 0.31$ & $2.42 \pm 0.39$ \\
\hline Diabetics $(n=6)$ & $1.63 \pm 0.13$ & $1.62 \pm 0.13$ & $1.54 \pm 0.08$ & $1.68 \pm 0.07$ & $1.84 \pm 0.12$ \\
\hline \multicolumn{6}{|c|}{ Forearm alanine balance $\neq\left(\mu g \cdot\right.$ liter $\left.^{-1} \cdot \mathrm{min}^{-1}\right)$} \\
\hline Controls $(n=6)$ & $-243 \pm 83$ & $-221 \pm 172$ & $+50 \pm 59$ & $+66 \pm 44$ & $-15 \pm 42$ \\
\hline Diabetics $(n=6)$ & $-187 \pm 26$ & $-159 \pm 44$ & $-198 \pm 66$ & $-166 \pm 43$ & $-120 \pm 44$ \\
\hline
\end{tabular}

* Data are mean \pm SE. $¥$ The signs + and - indicate a net uptake or output, respectively.

as was C-peptide. The possibility should, however, be considered that the residual plasma insulin, at a time when the C-peptide levels were nearly zero, may represent more an artifact of the radioimmunoassay than a true biological activity. On the other hand, the rapid and remarkable increase of blood beta-hydroxybutyrate observed in both groups of subjects could not be compatible with a persisting, near-basal insulinization.

Another problem which should be considered relates to the fact that insulin action may persist at tissue level once the hormone has disappeared from the circulation. Extensive evidence, in fact, indicates that deactivation of insulin action occurs slowly after tissue exposure to hyperinsulinemia (20-23). This problem, however, does not appear to be directly applicable to the present situation of basal insulinization. On the other hand, the observation that the forearm $\mathrm{A}-\mathrm{dV}$ glucose difference and glucose uptake fell drastically after 60 min of SRIF infusion strongly argues against the possibility of a significant residual insulin action.

The marked fall in forearm glucose uptake after infusion of SRIF while maintaining euglycemia, was a collateral finding which, however, deserves some comments. Although this issue was not specifically addressed in initiating this study, the data unequivocally lead to the conclusion that the small degree of peripheral insulinization in the postabsorptive state plays an essential role in maintaining muscle glucose uptake. Whether this

Table IV. Forearm Blood Flow $\left(\mathrm{ml} \cdot \mathrm{liter}^{-1} \cdot \mathrm{min}^{-1}\right)$ in Control and Diabetic Subjects during Infusion of SRIF and Glucose

\begin{tabular}{clllll}
\hline & 0 & 60 & 90 & 120 & 150 \\
\hline & $\min$ & $\min$ & $\min$ & $\min$ & $\min$ \\
$\begin{array}{c}\text { Controls } \\
(n=6)\end{array}$ & $40 \pm 5.5$ & $44 \pm 10$ & $39 \pm 8.8$ & $40 \pm 6.4$ & $37 \pm 5.6$ \\
$\begin{array}{c}\text { Diabetics } \\
(n=6)\end{array}$ & $33 \pm 3.5$ & $34 \pm 7.3$ & $37 \pm 6.1$ & $36 \pm 4.8$ & $32 \pm 4.6$ \\
\hline
\end{tabular}

* Data are mean $\pm \mathrm{SE}$. represents a distinct effect of insulin per se or an indirect mechanism activated by insulinopenia remains to be established.

Previous studies demonstrated that under conditions of euglycemic insulinopenia similar to those of our study, total glucose utilization declined by $15-20 \%$, and this response was entirely attributable to a decrease in glucose oxidation (24). The current study extends these observations by demonstrating that the muscle tissue contributes to this phenomenon.

The main finding of the present study is the remarkable increase in muscle glucose uptake brought about by hyperglycemia despite insulin deficiency. Similar data were already available in normal subjects (1), although the current approach is more adequate to evaluating the effect of glucose per se as a $60-\mathrm{min}$ period of insulinopenia preceded the induction of hyperglycemia. Nevertheless, the magnitude of the increase in muscle glucose uptake was very comparable in the two studies. In contrast, the response of type II diabetics differed markedly in that glucose uptake was stimulated to a significantly greater extent than in control subjects, although the difference was not sustained but tended to wane by the end of the study period. Therefore, not only does hyperglycemia operate regularly in type II diabetes,

Table V. Arterial Blood Glucose Concentration, A-dV Blood Glucose Difference, and Forearm Glucose Uptake during Intraarterial Infusion of SRIF Alone*

\begin{tabular}{|c|c|c|c|}
\hline & \multirow{2}{*}{$\frac{\mathrm{SRIF}(3.6 \mu \mathrm{g} / \mathrm{h})}{0(\mathrm{~min})}$} & \multicolumn{2}{|c|}{ SRIF $(7.2 \mu \mathrm{g} / \mathrm{h})$} \\
\hline & & $20(\mathrm{~min})$ & $40(\mathrm{~min})$ \\
\hline $\begin{array}{l}\text { Arterial blood glucose } \\
\qquad(m g / d l)\end{array}$ & $77 \pm 2.6$ & $77 \pm 1.5$ & $76 \pm 1.1$ \\
\hline $\begin{array}{l}\text { A-dV blood glucose } \\
\text { difference }(m g / d l)\end{array}$ & $4 \pm 0.67$ & $5 \pm 0.56$ & $5 \pm 0.64$ \\
\hline $\begin{array}{l}\text { Forearm glucose uptake } \\
\left(\mathrm{mg} \cdot \mathrm{liter}^{-1} \cdot \mathrm{min}^{-1}\right)\end{array}$ & $1.8 \pm 0.18$ & $2.2 \pm 0.31$ & $2.3 \pm 0.34$ \\
\hline
\end{tabular}

* Data are mean $\pm \mathrm{SE}$. 
but the possibility also emerges that it plays a compensatory role for the well-documented defective insulin action in this disease (2-6). Strictly speaking, these considerations should be confined to the forearm tissues which, under the present conditions, are prevalently represented by the skeletal muscle. Note, on the other hand, that the muscle tissue is by far the primary site in the peripheral disposal of a glucose load, as the adipose tissue takes up negligible amounts of glucose (7). Therefore, the compensatory effect of hyperglycemia per se presently seen in the forearm is very likely to play a definite role in the context of the overall peripheral glucose disposal in type II diabetes.

Recent studies comparing the response to the euglycemic and hyperglycemic insulin clamp in type II diabetics have reported that hyperglycemia partially compensates for the decrease in insulin-stimulated glucose uptake (25). From this observation, a compensatory role for the mass action effect of glucose in type II diabetes has been inferred. Our data are in perfect agreement with this view. However, it should be stressed that what previous studies (25) have really examined is the interaction of hyperglycemia with insulin stimulatory effect on glucose uptake rather than the pure mass action effect of glucose. In other words, those studies do document a potentiating effect of hyperglycemia on insulin-stimulated glucose uptake, but do not face the question whether the glucose mass action is primarily altered in type II diabetes. Obviously, for the glucose mass action to be appropriately explored as an individual component, it is necessary that hyperglycemia operates in a situation of insulin lack. Although such a condition is unfeasible in vivo, the current approach allows the deepest degree of insulinopenia to be reached in a human study. In this situation, the observed effects on forearm glucose metabolism can be safely attributed to hyperglycemia per se rather than to glucose-insulin interaction.

The mechanism by which hyperglycemia stimulates muscle glucose uptake to a greater extent in diabetics as compared with normal subjects remains to be elucidated. One possibility is that the condition of hyperglycemia to which untreated diabetics are chronically exposed could induce slow adaptive changes by enhancing the efficiency of the glucose transport system or activating some enzymatic systems capable of being affected by glucose concentration per se (26-28).

Regarding the fate of the glucose taken up by the muscle tissue, three major metabolic pathways should be considered: (1) oxidation to carbon dioxide and water; (2) storage as glycogen; and (3) conversion to three carbon compounds. In the present study, the third possibility was investigated directly by measuring the forearm balance of the two major substrates, namely, lactate and alanine. In both groups of subjects, the forearm production of these substrates failed to increase, suggesting that the glycolytic flux was not accelerated, in spite of the increased glucose disposal. This finding is in accordance with previous studies that demonstrate that the oxidative pathway of glucose metabolism is strictly dependent on insulin availability (24). Furthermore, it is known that, at high rates of glucose uptake, the ability of muscle tissue to oxidize glucose is limited, with glucose storage representing the major route of glucose disposal (29). Therefore, although complete oxidation to carbon dioxide and water cannot be excluded, it is more likely that under the present condition of hyperglycemia associated with insulin deficiency, the majority of glucose taken up by the muscle tissue was primarily stored rather than oxidized. This interpretation would be also supported by previous studies demonstrating the ability of glucose per se to regulate the activity of enzymes involved in the glycogen syn- thesis pathway, independent of changes in insulin availability (26-28). Finally, of particular interest is the fact that the response of forearm alanine output closely paralleled that of lactate. This finding is not surprising, however, considering that alanine synthesis in the skeletal muscle occurs prevalently at expense of glycolysis-derived pyruvate, and to a lesser extent is a reflection of proteolysis $(30,31)$.

The possibility that SRIF per se may influence forearm glucose metabolism has been directly examined in the present study by infusing the peptide into the brachial artery. Consistent with previous in vitro studies (32) is the present observation that SRIF is unable to alter glucose uptake by muscle tissue. Furthermore, SRIF is known to inhibit the secretion of a variety of hormones, including glucagon and growth hormone. In this regard, many previous studies have shown that the acute deficiency of these hormones induced by SRIF has no demonstrable effect on glucose utilization (33-35). Recent data, however, seem to suggest that in the dog, acute growth hormone deficiency could be responsible for the increased glucose utilization observed during somatostatin infusion. Therefore, the possibility that in our study growth hormone deficiency may have led to a potentiation of hyperglycemia-induced glucose disposal cannot be excluded with certainty. In any event, it is unlikely that this phenomenon may have exerted a significant effect on the observed difference between control and diabetic subjects (36).

In summary, the present study indicates that hyperglycemia per se is able to stimulate glucose uptake by the forearm to a considerable extent in type II diabetes. The current data thus support a possible role of hyperglycemia in compensating for the defective glucose disposal in this disease.

\section{Acknowledgments}

The authors thank Mr. Ciro Iovine from the Department of Internal Medicine, University of Naples, for insulin and C-peptide assay.

This work was supported in part by a grant from the Consiglio Nazionale delle Ricerche (Italy) (contracts 83.02811.56 and 84.02501.56).

\section{References}

1. Saccà, L., M. Cicala, B. Trimarco, B. Ungaro, and C. Vigorito. 1982. Differential effects of insulin on splanchnic and peripheral glucose disposal after an intravenous glucose load in man. J. Clin. Invest. 70 : 117-126.

2. Ginsberg, H., G. Kimmerling, J. M. Olefsky, and G. M. Reaven. 1975. Demonstration of insulin resistance in maturity onset diabetic patients with fasting hyperglycemia. J. Clin. Invest. 55:454-461.

3. Reaven, G. M., R. Berstein, B. Davis, and J. M. Olefsky. 1976. Non-ketotic diabetes mellitus: insulin deficiency or insulin resistance. Am. J. Med. 60:80-88.

4. DeFronzo, R. A., D. Deibert, R. Hendler, P. Felig, and V. Soman. 1979. Insulin sensitivity and insulin binding in maturity onset diabetes. J. Clin. Invest. 63:939-946.

5. Rizza, R. A., L. J. Mandarino, and J. E. Gerich. 1981. Mechanism and significance of insulin resistance in non-insulin-dependent diabetes mellitus. Diabetes. 30:990-995.

6. Kolterman, O. G., R. S. Gray, J. Griffin, P. Burstein, J. Insel, J. A. Scarlett, and J. M. Olefsky. 1981. Receptor and postreceptor contribute to the insulin resistance in noninsulin-dependent diabetes mellitus. J. Clin. Invest. 68:957-969.

7. Bjontorp, P., and L. Sjostrom. 1978. Carbohydrate storage in man: speculations and some quantitative considerations. Metab. Clin. Exp. 27(Suppl. 2):1853-1863. 
8. National Diabetes Data Group. 1979. Classification and diagnosis of diabetes mellitus and other categories of glucose intolerance. Diabetes. 28:1039-1057.

9. Andres, R., K. L. Zierler, H. M. Anderson, W. N. Stainsby, G. Cader, A. S. Ghrayyib, and J. L. Lilienthal, Jr. 1954. Measurement of blood flow and volume in the forearm of man; with notes on the theory of indicator-dilution and on production of the turbulence, hemolysis, and vasodilatation by intravascular injection. J. Clin. Invest. 33:482504.

10. Zierler, K. L., and D. Rabinowitz. 1962. Role of insulin and growth hormone, based on studies of forearm metabolism in man. Med icine (Balt.). 42:385-402.

11. Huggett, A. S. G., and D. A. Nixon. 1957. Use of glucose oxidase, peroxidase, and o-dianisidine in determination of blood and urinary glucose. Lancet. II:368-370.

12. Debuquois, B., and G. D. Aurbach. 1971. Use of polyethylene glycol to separate free and antibody bound peptide hormones in radioimmunoassay. J. Clin. Endocrinol. Metab. 33:732-738.

13. Heding, L. D. 1975. Radioimmunological determination of human C-peptide in serum. Diabetologia. 11:541-547.

14. Gutmann, I., and A. W. Wahlefeld. 1974. L-(+)-Lactate determination with lactate dehydrogenase and NAD. In Methods of Enzymatic Analysis. H. U. Bergmeyer, editor. Second ed. Academic Press, Inc., New York. 1464-1468.

15. Williamson, D. H. 1974. L-alanine determination with alanine dehydrogenase. In Methods of Enzymatic Analysis. H. U. Bergmeyer, editor. Second ed. Academic Press, Inc., New York. 1679-1682.

16. Williamson, D. H., and J. Mellanby. 1974. D-(-)-3-hydroxybutyrate. In Methods of Enzymatic Analysis. H. U. Bergmeyer, editor Second ed. Academic Press, Inc., New York. 1836-1839.

17. Butterfield, W. J. H., and H. E. Holling. 1959. Peripheral glucose metabolism in fasting control subjects and diabetic patients. Clin. Sci. 18:147-174.

18. Wallenstein, S., C. L. Zucker, and J. L. Fleiss. 1980. Some statistical methods useful in circulation research. Circ. Res. 47:1-9.

19. Saccà, L., G. Orofino, A. Petrone, and C. Vigorito. 1984. Direct assessment of splanchnic uptake and metabolic effects of human and porcine insulin. J. Clin. Endocrinol. Metab. 59:191-196.

20. Sherwin, R. S., K. J. Kramer, J. D. Tobin, P. A. Insel, J. E. Liljenquist, M. Bowman, and R. A. Andres. 1974. A model of the kinetics of insulin in man. J. Clin. Invest. 53:1481-1492.

21. Zierler, K. R., and D. Rabinowitz. 1964. Effect of very smal concentrations of insulin on forearm metabolism. Persistence of its action on potassium and free fatty acids without its effect on glucose. J. Clin. Invest. 43:950-962.

22. Gray, O. G., J. A. Scarlett, J. Griffin, J. M. Olefsky, and O. G.
Kolterman. 1982. In vivo deactivation of peripheral, hepatic, and pancreatic insulin action in man. Diabetes. 31:929-936.

23. Fineberg, S. E., and S. H. Schneider. 1982. Studies on the relationship between insulin concentrations and insulin action. Diabetes Care. 5:292-299.

24. Felber, J. P., D. Thièbaud, E. Maeder, E. Jéquier, R. Hendler, and R. A. DeFronzo. 1983. Effect of somatostatin-induced insulinopenia on glucose oxidation in man. Diabetologia. 25:325-330.

25. Revers, R. R., R. Fink, J. Griffin, J. M. Olefsky, and O. G. Kolterman. 1983. Influence of hyperglycemia on insulin's in vivo effects in type II diabetes. J. Clin. Invest. 73:664-672.

26. Hess, H. C. 1976. The control of glycogen metabolism in the liver. Ann. Rev. Biochem. 45:167-189.

27. Buschiazzo, H., J. H. Exton, and C. R. Park. 1970. Effects of glucose on glycogen synthetase, phosphorylase, and glycogen deposition in the perfused rat liver. Proc. Natl. Acad. Sci. USA. 65:383-387.

28. Holmes, P. A., and T. E. Mansour. 1968. Effect of glucose and related compounds on phosphorylase and glycogen levels. Biochim. Biophys. Acta. 156:266-274.

29. Thièbaud, D., E. Jacot, R. A. DeFronzo, E. Maeder, E. Jéquier, and J. P. Felber. 1982. The effect of graded doses of insulin on total glucose uptake, glucose oxidation, and glucose storage in man. Diabetes. 31:957-963.

30. Chang, T. W., and A. L. Goldberg. 1978. The origin of alanine produced in skeletal muscle. J. Biol. Chem. 253:3677-3684.

31. Odessey, R., E. A. Khairallah, and A. L. Goldberg. 1974. Origin and possible significance of alanine production by skeletal muscle. $J$. Biol. Chem. 249:7623-7629.

32. Cherrington, A. D., M. D. Caldwell, M. R. Dietz, J. H. Exton, and O. B. Crofford. 1977. The effect of somatostatin on glucose uptake and production by rat tissue in vitro. Diabetes. 26:740-748.

33. Cherrington, A. D., J. E. Liljenquist, G. I. Shulman, P. E. Williams, and W. W. Lacy. 1979. Importance of hypoglycemia-induced glucose production during isolated glucagon deficiency. Am. J. Physiol. 236(3):263-271.

34. Cherrington, A. D., J. L. Chiasson, J. E. Liljenquist, A. S. Jennings, U. Keller, and W. W. Lacy. 1976. The role of insulin and glucagon in the regulation of basal production in the postabsorptive dog. J. Clin. Invest. 58:1407-1418.

35. Rizza, R. A., P. E. Cryer, and J. E. Gerich. 1979. Role of glucagon, catecholamines, and growth hormone in human counterregulation. Effects of somatostatin and combined $\alpha$ - and $\beta$-adrenergic blockade on plasma glucose recovery and glucose flux rates after insulin-induced hypoglycemia. J. Clin. Invest. 64:62-71.

36. Bergman, R. N., M. Ader, D. T. Finegood, and G. Pacini. 1984. Extrapancreatic effect of somatostatin infusion to increase glucose clearance. Am. J. Physiol. 247(10):370-379. 